DOI: $10.52950 /$ SS.2021.10.1.005

\title{
SUICIDE DURING THE COVID-19 PANDEMIC, A PRELIMINARY ANALYSIS IN THE STATE OF TAMAULIPAS, MEXICO
}

\section{KARLA VILLARREAL-SOTELO}

\begin{abstract}
:
Due to the increase in suicide cases during the SARS-CoV-2 (Covid-19) pandemic reported in digital media such as social networks and newspapers, the present study aims to preliminarily identify the frequency of suicide cases during the pandemic of Covid-19 in the period January-December 2020 in the state of Tamaulipas, Mexico. We analyze the official suicide figures registered in the Secretary of Health of the State of Tamaulipas and the official epidemiological data available on the Government of Mexico Website. We found that in the study period, suicide deaths in the state have exceeded the total of suicide deaths in 2019; In addition, the frequency of cases was higher in men than in women, we identified two increases in the frequencies of suicides in the state: one month after entering a health contingency and during the highest record of infections by Covid-19. We conclude that it is urgent to guarantee the mental health of people, especially in urban areas, derived from the increase in suicide cases registered in cities.
\end{abstract}

\section{Keywords:}

COVID-19, suicide, pandemic, mental illness, prevention, mental health, victimology

JEL Classification: $110,114,118$

\section{Authors:}

KARLA VILLARREAL-SOTELO, Universidad Autónoma de Tamaulipas, Mexico, Email: kvillar@uat.edu.mx

\section{Citation:}

KARLA VILLARREAL-SOTELO (2021). Suicide during the Covid-19 pandemic, a preliminary analysis in the State of Tamaulipas, Mexico . International Journal of Social Sciences, Vol. X(1), pp. 88-101., 10.52950/SS.2021.10.1.005

This study was funded by the Autonomous University of Tamaulipas within the framework of the Project 38INVESTUAT2020 "Suicide in times of COVID-19: a victimological interpretation". 


\section{Introduction}

According to the World Health Organization (WHO) (2020), suicide is defined as death caused by self-directed injurious behavior with intent to die as a result of the behavior, this action is considered serious and harmful both for the individual who commits it and for his environment, since every suicide is a tragedy that affects families, communities and entire countries and has long-lasting effects on the people left behind, which is why it represents a public health problem of global relevance, with a rate of 800 thousand deaths each year being the second cause number of deaths in young people between 15 and 29 years of age (WHO, 2020). The suicide mortality rate (11.4 deaths per 100 thousand inhabitants) has placed it as an indicator of Goal 3: Health and Well-being of the Sustainable Development Goals due to the heterogeneity of factors that are immersed in this phenomenon.

Currently the pandemic caused by the severe acute respiratory syndrome coronavirus 2 (SARSCoV-2), also known as the Corona Virus Disease 2019 (COVID-19), has led to the implementation of various strategies to reduce contagion between people and the regions, becoming a serious public health problem that has impacted on people's lives not only in the health aspect, but also economically, socially and environmentally. The main strategies taken by the governments of most countries in the world have been isolation, personal protection (biosecurity), early diagnosis and treatment (for symptoms) in infected patients (Macintosh, 2020). However, the consequences on people's mental health, especially suicide, and that could be caused by: 1) infections, which add up to around 50 million people and more than a million deaths from COVID-19 globally, and the social exclusion of people due to fear of contagion, 2) measures to prevent the spread of COVID19 such as isolation, quarantine and curfew, 3) economic losses and unemployment, and 4) deaths of family, friends and acquaintances (Griffiths \& Mamun, 2020, Brown and Shuman, 2020 Sher, 2020, D'Souza et al. 2020).

In addition, there is evidence of an increase in suicide cases in the United States during the influenza pandemic of 1918-1919 (Wasserman, 1992), suicides of older adults in Hong Kong during the SARS pandemic in 2003 (Cheung, Chau \& Yip, 2008) and according to the Pan American Health Organization (PAHO) (2020) the COVID-19 pandemic affects people's mental health, which may represent an important factor for public health and consequently, suicides.

However, Leaune et al. (2020) establish that the documented evidence of the increase in suicides during pandemics is scarce, which represents a field still in exploration of the correlation between these phenomena. In relation to the COVID-19 pandemic and suicides, Mamun \& Griffiths (2020) 
documented a case of suicide in Bangladesh, due to the social exclusion of a group for fear of being infected by members of another social group of the region, Goyal et al. (2020) reported another suicide case, this time in India, a man committed suicide by hanging to avoid spreading Covid-19 throughout the village, as well as the records of hemerographic notes of suicides reported by D'Souza et al. (2020) in India. Consequently, the monitoring of the fluctuations of suicide cases during the COVID-19 pandemic has a special relevance to understand the psychosocial implications of the pandemic focused on the study of suicide (Xiang et al. 2020).

\subsection{Suicide in Mexico}

In Mexico, the suicide death rate has been increasing in 2011-2018 period, in such a way that by 2018 the suicide death rate was 5.4 per 100 thousand inhabitants, 2018 being the year with the highest number of suicides (National Institute of Statistic and Geography INEGI, 2019) (Figure 1). According to data from INEGI (2019), the states with the highest number of cases of suicide deaths were Yucatán (10.6), Aguascalientes (10.0) and Chihuahua (9.8).

Figure 1.- Rate of suicide deaths in México in the period 2011-2018

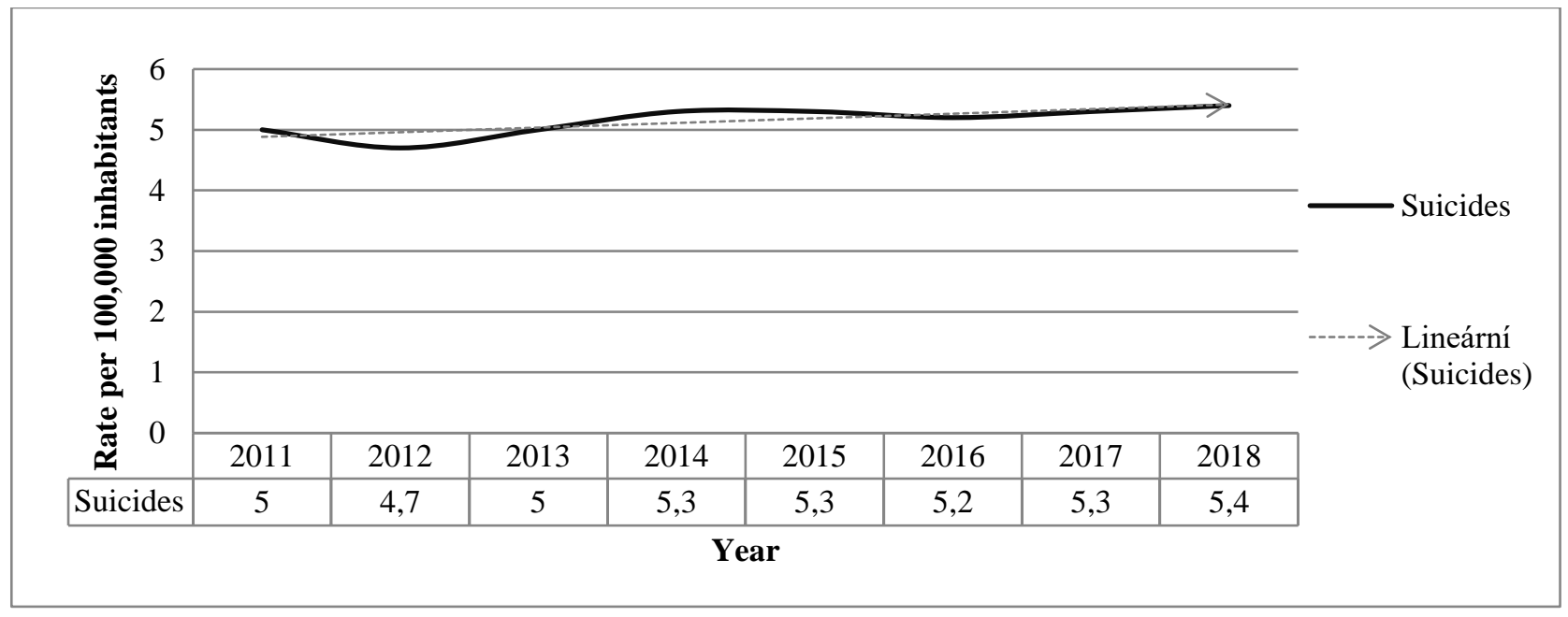

Source: authors, with information from INEGI (2019a)

Demographic characteristics of the 6,808 deaths by suicide in $2018,18.6 \%(n=1,265)$ correspond to women, while $81.4 \%(n=5,540)$ correspond to men. Furthermore, the identified age ranges were $25-34$ years of age $(27 \%, n=1419)$ and $15-24$ years of age $(25 \%, n=1397)$. The reported suicide methods were hanging $80.6 \%(n=5486)$, firearms $7.6 \% \quad(n=515)$, poisoning $7.4 \%(n=506)$ and "others" with $4.4 \%$ ( $n=301)$ in which include suicides by falling, stabbing, suffocation by submersion and car crash (INEGI, 2019a). 
Statistical reports of INEGI (2019) establish that suicide is the second cause of death in people between 15 and 29 years of age and the fifth cause of death in people between 30-34 years of age, so this cause of death it ranks 22 nd on the list of the main causes of death in the population of Mexico.

According to hemerographic reports derived from interviews with the National Health Center and the Youth Integration Centers (ClJ for its acronym in Spanish), an increase of $43 \%$ in suicide cases in young people in the range of 15 to 29 years is estimated of age during the COVID-19 pandemic in Mexico (Infobae, 2020); however, official figures for suicides nationwide during the pandemic have not been officially published. Hemerographic notes of interviews with the Ministry of Health have been published in which it is established that the telephone line "Línea de Vida" in charge of the Ministry of Health of Mexico, the calls related to self-harm and suicide attempts have increased in the period January-August 2020 and registering a total of 2,130 deaths by suicide in Mexico until September 2020 (Political Expansion, 2020).

\subsection{Suicide in Tamaulipas}

The standardized suicide rate in the state of Tamaulipas is 4.6 people per 100 thousand inhabitants (INEGI, 2019a), the frequency of deaths by suicide has been fluctuating downward since 2011, with 2012 and 2016 being the ones that have had fewer cases (Figure 2).

Figure 2.- Frequencies of suicide cases in the state of Tamaulipas Mexico in the period 20112019

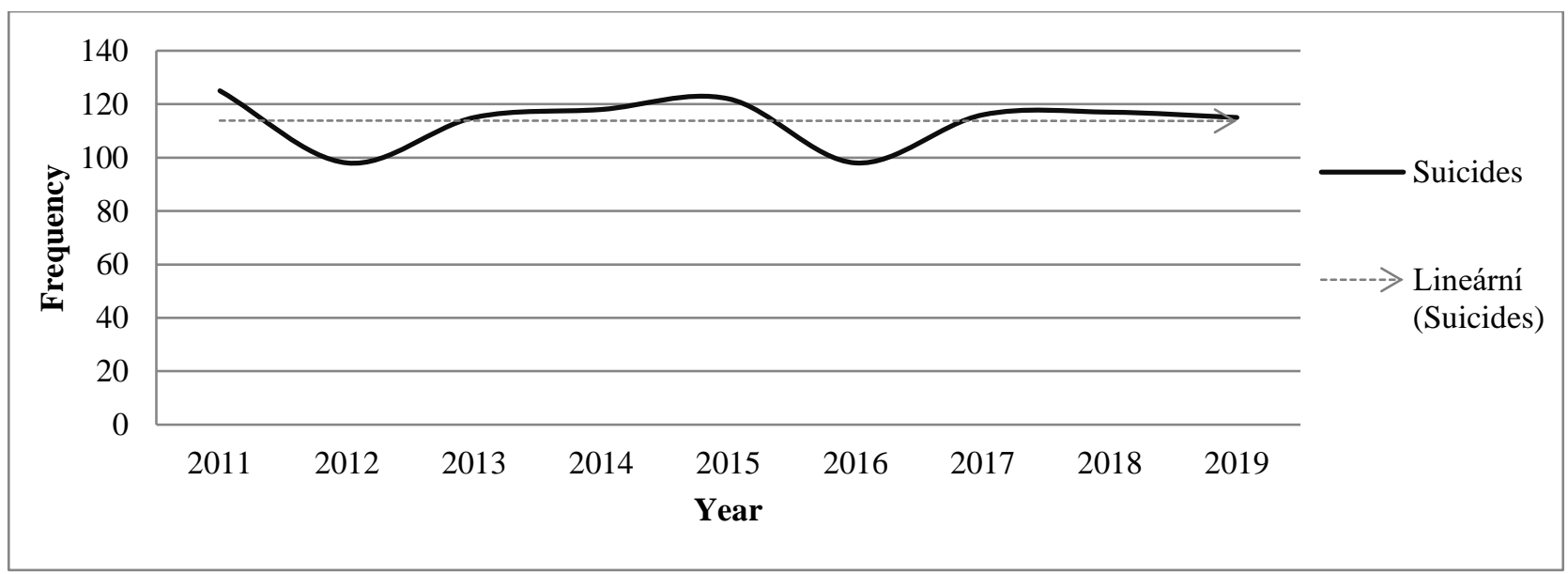

Source: authors, with information from the Secretary of Health of the state of Tamaulipas (2020)

It was reported that during 2019 in the state of Tamaulipas, the age ranges with high rates of suicide deaths are between 20-29 years of age ( $n=165), 30$-39 years of age $(n=190)$ and $40-49$ years of 
age $(n=130)$. In addition, the representation by gender was headed by men ( $89 \%)$ while women represent $11 \%$ of the total suicides in 2019 . The suicide methods identified were: hanging, firearms and intoxicated by drugs or poison (Secretary of Health of the state of Tamaulipas, 2020).

Historical statistics of suicides in the state have shown that summer is the time with the highest incidence of deaths by suicide in the state, the months of March-August have the highest suicide rates, compared to the months with lower temperatures, since increased irritability, impatience, low tolerance for frustration and impulsivity and increased consumption of alcoholic beverages are all indirect consequences of the effects of high temperatures on the state during the summer (Secretary of Health of the state of Tamaulipas, 2020).

Therefore, the objective of this study is to preliminarily identify the frequency of suicide cases during the SARS-CoV-2 (Covid-19) pandemic in the period January-August 2020 in the state of Tamaulipas, Mexico.

\section{Methods}

\subsection{Type of study}

A descriptive, cross-sectional study was conducted to preliminarily identify the frequency of suicide cases during the Covid-19 pandemic in the period January-August 2020 in the state of Tamaulipas, Mexico.

\subsection{Inclusion and exclusion criteria}

Inclusion criteria were a) the official epidemiological data available on the website of the Government of Mexico (https://datos.covid-19.conacyt.mx/\#SemaFE) to identify the fluctuation of cases of COVID-19 infections in the state of Tamaulipas during the period January-August 2020 and b) official records of suicide cases of the Secretary of Health of the State of Tamaulipas in the period January-August 2020. Based on the Columbia Classification Algorithm of Suicide Assessment (C-CASA) (Posner et al., 2007; Turecki and Brent, 2016; Leaune et al. 2020) for suicide studies, we used the classification "suicidal behaviors" represented by suicide deaths in the database provided preliminarily by the Secretary of Health of the State of Tamaulipas, which only includes the suicide death records, so the suicide attempts are an exclusion criterion in the present study. 


\subsection{Data Analysis}

The data obtained were analyzed by descriptive statistics, the epidemiological data of the frequency of COVID-19 cases in the state of Tamaulipas, were divided by month, to make the comparison with the data reported on suicides in the same study period. Of the suicide cases, the variables were analyzed: age range, gender, municipality and mechanics of death.

\subsection{Clarification}

The suicide data presented in this preliminary study represent the total number of suicide cases at the state level and do not represent cases directly correlated with Covid-19 infections, but rather allow to raise the relevance of paying attention to the convergence of these two phenomena and the statistical behavior of both to identify possible correlations.

\section{Results and Discussion}

\subsection{Suicide epidemiology during the COVID-19 pandemic}

In the study period (January-December 2020), 223 cases of suicide have been reported in the state of Tamaulipas, however, no case of suicide has been identified in the state that is directly related to Covid-19, although not the influence of any of the consequences of the pandemic is ruled out, as in the cases reported by Mamun \& Griffiths (2020) and Goyal et al. (2020). We identify that the number of suicides in the state during the study period shows an increase of $93.99 \%$ in suicide cases respect to the annual total reported by the Secretary of Health of the State of Tamaulipas during 2019 ( $n=115$ ), which allows establishing that the first eight months of 2020 have exceeded the annual suicide rate of the last 9 years (Figure 2). 
Figure 2.- Frequency of suicide deaths in Tamaulipas Mexico in the period 2011-2020

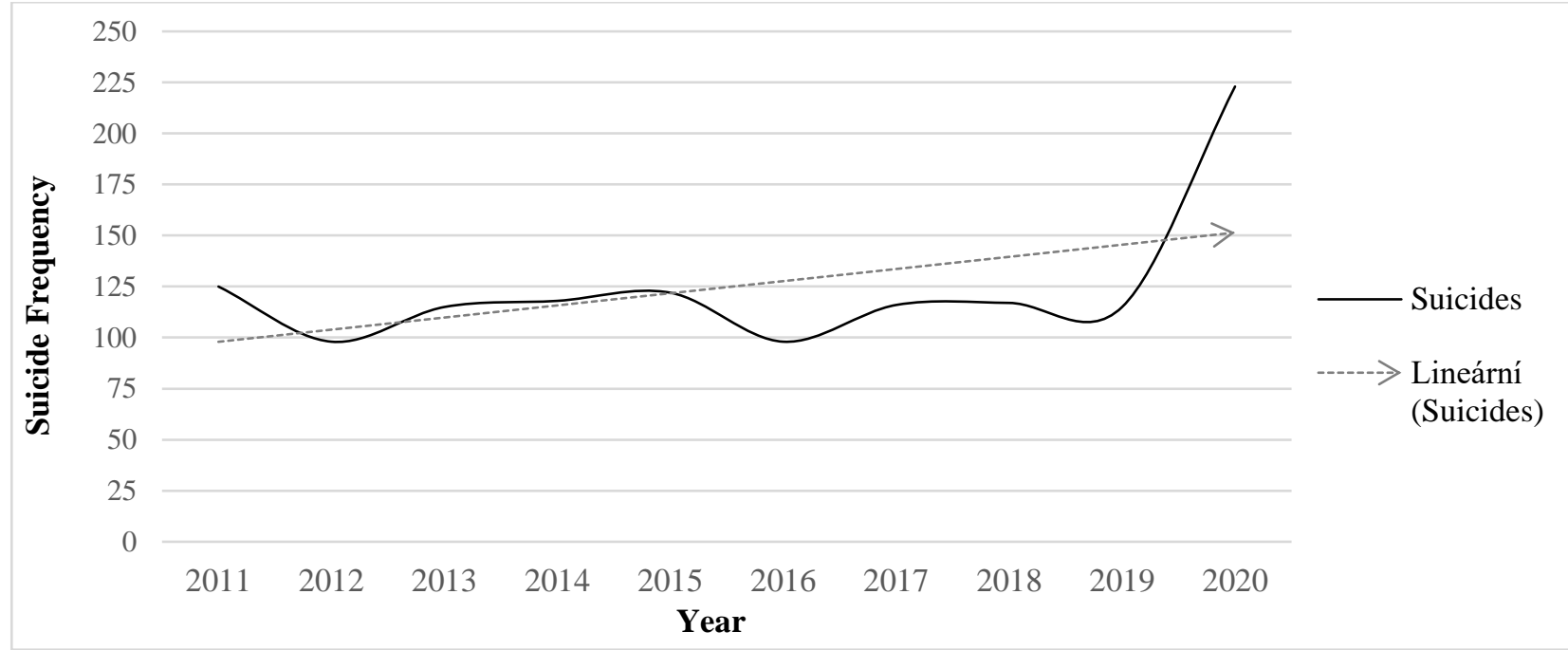

Source: authors, with information from the Secretary of Health of the State of Tamaulipas (2020)

In the study period (2020), February had the lowest frequency of suicides $(n=13)$ while November had the highest number of suicides $(n=25)$ with an increase in cases in April $(n=23)$ and June ( $n=23$ ). Although the trend line of suicide death frequencies in 2020 presents a decreasing (Figure 3) the average of suicide deaths in 2020 was 18.5 cases per month, while the suicide deaths annual average during 2019 was 9.5 .

Figure 3.- Frequency of suicide deaths in Tamaulipas Mexico in the period January-August 2020

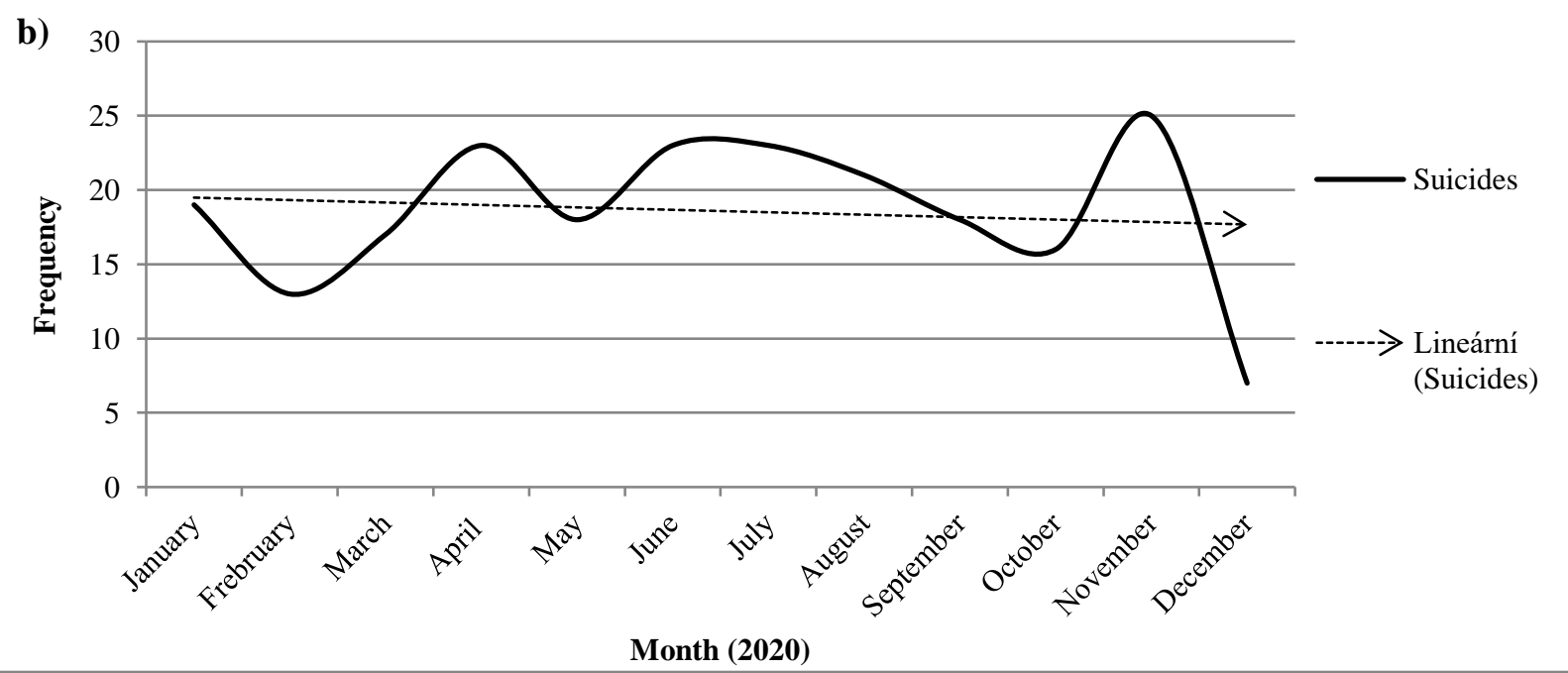

Source: authors, with information from the Secretary of Health of the State of Tamaulipas (2020) 
The differentiation by gender, men had $81.7 \%$ of cases of deaths by suicide reported in the study period, while women had $18.3 \%$ which is consistent with the statistics reported nationally and internationally in relation to the high frequency of suicides in men compared to women, as reported internationally by Dávila-Cervantes, Ochoa-Torres and Casique-Rodríguez, (2015), Chang, Yip and Chen (2019), WHO (2017) and at national level INEGI (2018) reported that the rate of deaths by suicide in men is 8.6 (per 100 thousand inhabitants) while in women it is 1.9 (per 100 thousand inhabitants)

The age data were provided by ranges, the youngest being 12 years old and the oldest 91 years old; regarding the months, April is the month with the suicide of the youngest person (12 years of age), while in the increase in cases during the month of July $(n=19)$ the case with the oldest age was reported (91 years of age) (Table 1).

Table 1.- Frequencies and age ranges of suicide deaths in the state of Tamaulipas during the period January-August 2020

\begin{tabular}{ccc}
\hline Month & $\begin{array}{c}\text { Suicides } \\
\text { deaths }\end{array}$ & Age Range \\
\hline January & 19 & $13-62$ \\
Frebruary & 13 & $17-75$ \\
March & 17 & $18-73$ \\
April & 23 & $12-85$ \\
May & 18 & $14-74$ \\
June & 23 & $17-61$ \\
July & 23 & $18-91$ \\
August & 21 & $26-60$ \\
September & 18 & $*$ \\
October & 16 & $*$ \\
November & 25 & $*$ \\
December & 7 & $*$ \\
\hline Total & 223 &
\end{tabular}

Source: authors, with information from the Secretary of Health of the State of Tamaulipas (2020)

*Data not available

We identified three methods of suicide in the state of Tamaulipas in this study period: hangin ( $n=89$, $67.9 \%$ ), firearms ( $n=38,29.0 \%$ ) and knives ( $n=4,3.1 \%$ ) (Figure 4$)$, which coincides with GutiérrezGarcía and Orozco-Rodríguez (2006:70) about epidemiological data such as prevalence, age and suicide methods used are influenced by different factors, generally those psychosocial, 
biopsychiatric and geographical location. Therefore, the methods identified in the present study coincide with the main suicide methods reported globally by the WHO (2020): hangings, firearms and the ingestion of pesticides.

Figure 4.- Frequency and accumulated percentage of suicide methods in the period JanuaryAugust 2020 in Tamaulipas

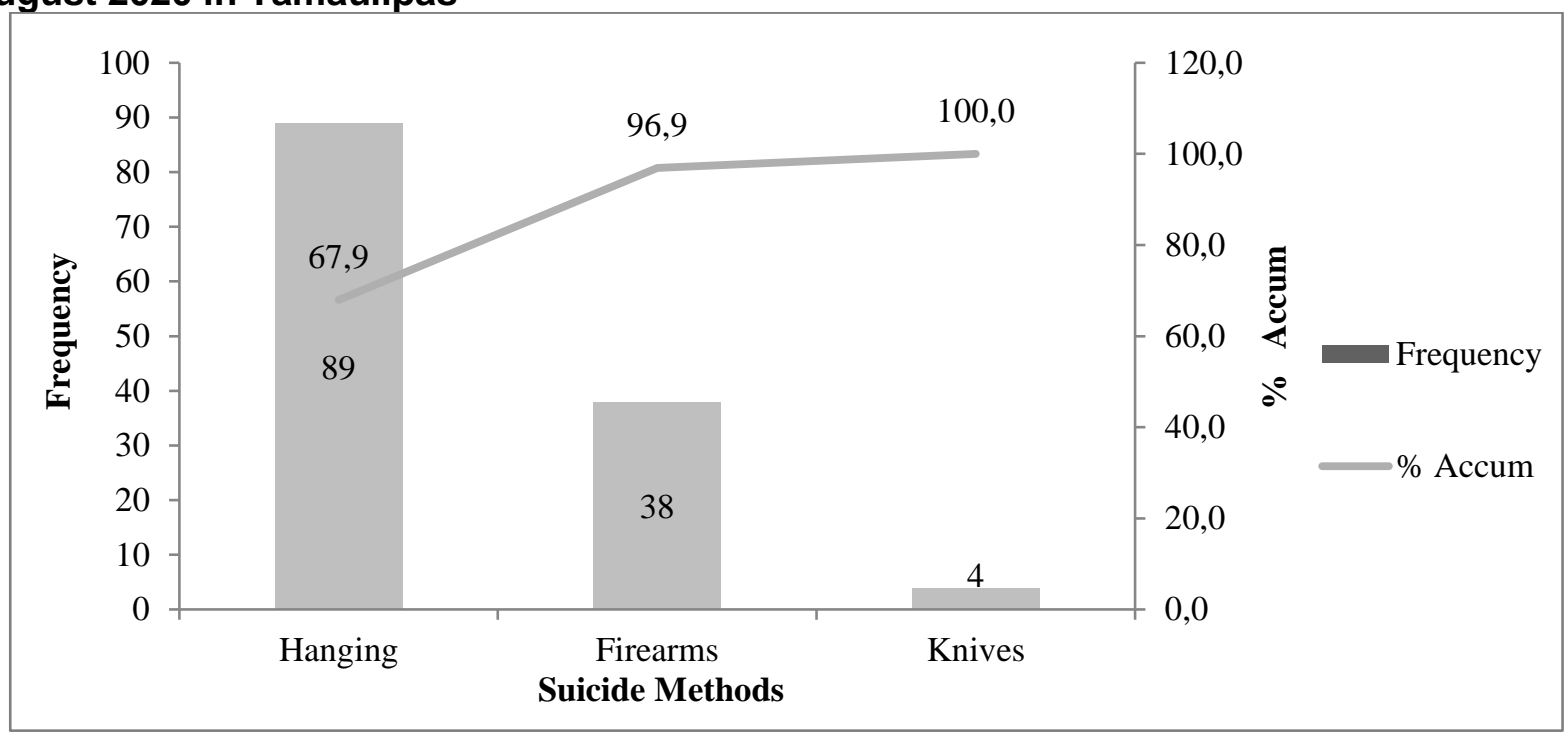

Source: authors, with information from the Secretary of Health of the State of Tamaulipas (2020)

In 2018 INEGI reported that the main methods for suicide in Mexico were hanging, representing $80.8 \%$ of suicides nationwide, while firearm shooting is the second most used method with $7.7 \%$; and in relation to the method-gender variables, $82.2 \%$ of the men used the hanging method and $8.8 \%$ was by firing a firearm, as for the women, $74.5 \%$ was by hanging and $13.3 \%$ by poisoning, ingest of pesticides, chemicals, drugs, medications and other chemical substances.

\subsection{Is there a correlation between suicide frequencies and covid-19 infections in Tamaulipas?}

The beginning of quarantine (social isolation and biosecurity) in the state of Tamaulipas was in March, derived from the first case of Covid-19 reported in the state in the port municipality of Altamira. Suicides during the first two months of 2020 averaged 14.5, while for the month of April the figure increased by $46 \%$ compared to March, being the month with the most deaths by suicide $(n=22)$ in the period of study.

The curve of increase of Covid-19 cases was increasing from March to July when it had its first peak of infections (10,834 cases) (Figure 4a); however, in the case of suicides, the behavior of the figures fluctuated, with a decrease in May and again increased in the June-July two-month period and November (Figure 4b). According to the records of the Secretary of Health of the State of 
Tamaulipas (2020) there is in the state a statistical historical record of the increase of suicide deaths in summer months, even so, two months of considerable increase in frequencies stand out of suicide within the period, which correspond to the second month of the beginning of infections by Covid-19 in the state (April) and the highest frequency of infections in the month of July, however, there was an increase in suicides in November in relation to the rest of the cases in the study period (Figure 4a-b).

Figure 4.- Comparison of behavior frequencies of registered cases of COVID-19 and suicides in Tamaulipas in the period January-August 2020
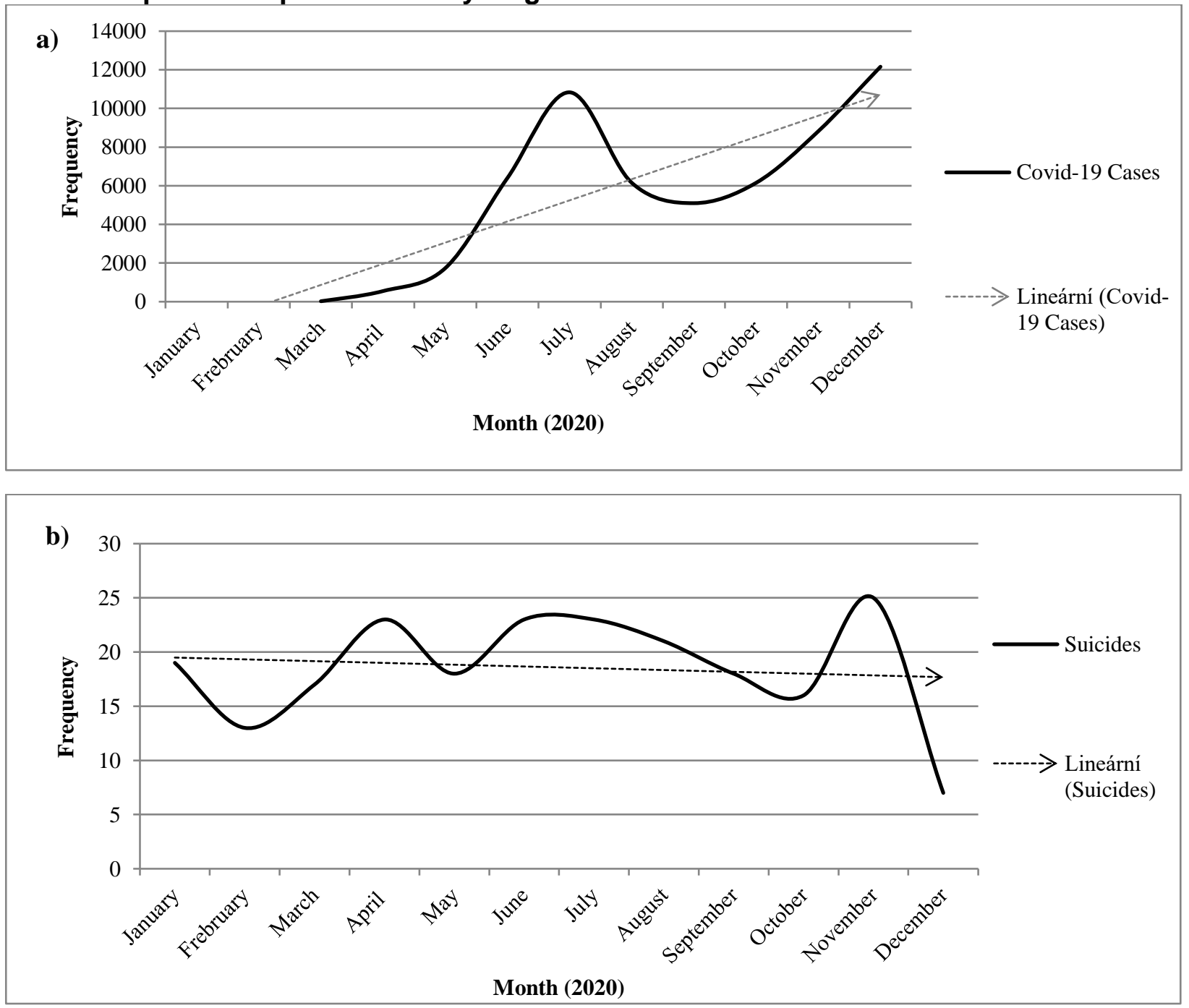

Source: authors, with information from the Secretary of Health of the State of Tamaulipas (2020) and official epidemiological data available on the Government of Mexico website.

Statistically there is no strong correlation between the increase in suicides and the frequencies of Covid-19 cases registered in the state $(r=0.27)$, however, it is not ruled out that there may be a correlation later, being of special interest the months of April and November due to the increase in 
suicides. Even so, the geographical distribution of the frequencies of both Covid-19 infections and suicides allow us to establish that they correspond to the municipalities with the highest population density in the state (Figure 5). Geographical distribution of suicide cases and Covid-19 infections have been concentrated in the cities of the municipalities in the north of the state, in the border region with the United States; while in the central and southern areas of the state they have remained in urban and port areas.

\section{Figure 5.- Geographical distribution of Covid-19 cases and suicide deaths in municipalities of Tamaulipas during January-August 2020}

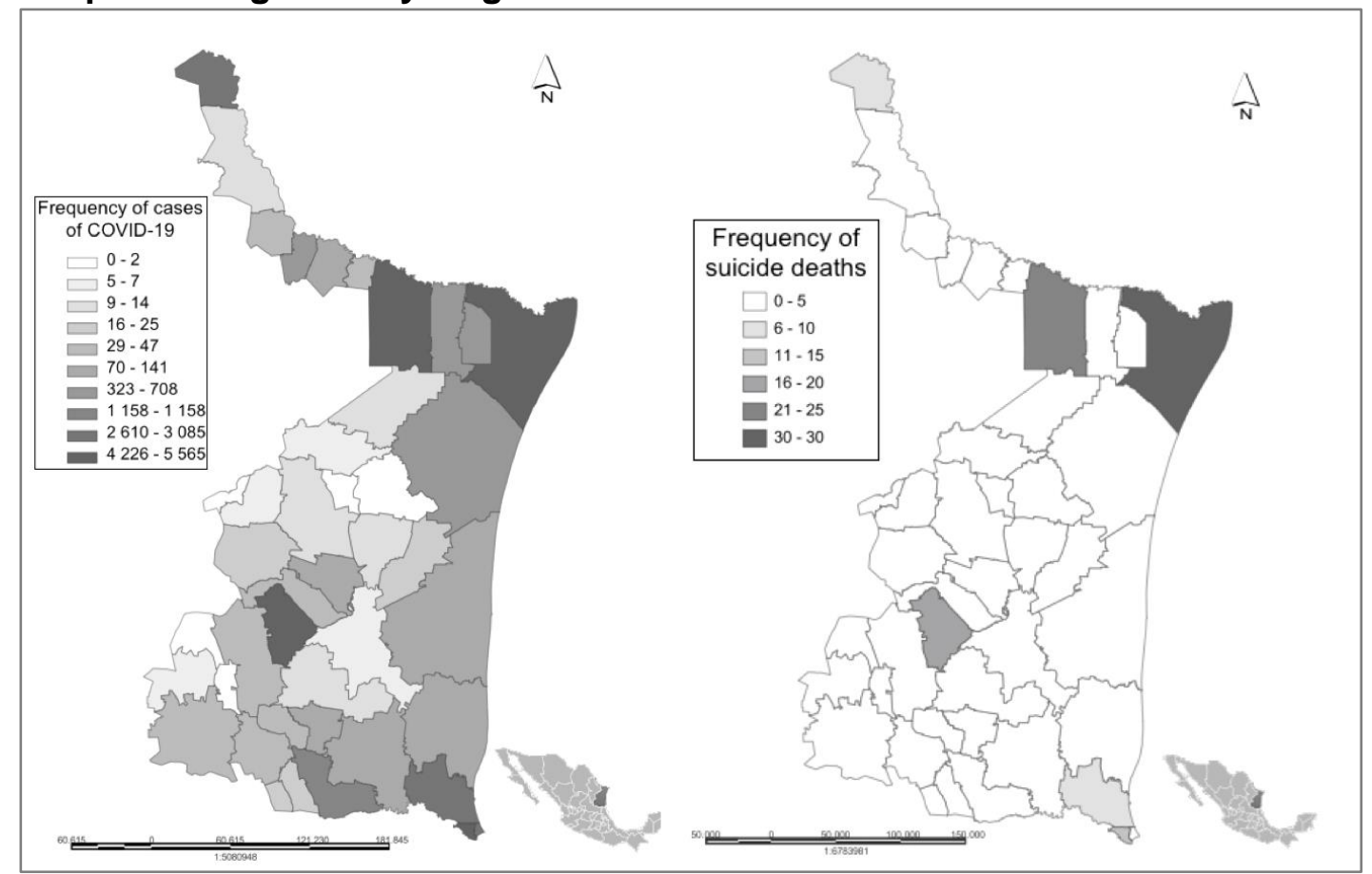

Source: authors, with information from the Secretary of Health of the State of Tamaulipas (2020) and official epidemiological data available on the Government of Mexico website.

This concentration of Covid-19 cases and suicides in urban areas of the state of Tamaulipas allows us to identify that the challenges of government agencies face a double challenge: guaranteeing the physical health of the population avoiding the contagion of Covid-19 and in turn, monitor and prevent suicide deaths. This coincides with that reported by Agnoletti, Manganelli and Piras (2020) and Sharifi and Khavarian-Garmsir (2020) related to concentration of Covid-19 infections in urban areas, while in rural settings they have been lower.

\section{Conclusions}

Probably many factors will increase suicide cases in the remainder of the pandemic, it is necessary to focus efforts also on the protection of mental health, as well as redirect public policies on social 
security towards the development of people with economic insecurity, promote government-society cohesion and communication in a way to guarantees the physical and emotional well-being of people of the state.

Remains pending to evaluate the effects of Covid-19 pandemic on Mexican national suicide records, to strengthen strategies to prevent suicide as well as to improve the mechanisms for analyzing the phenomenon, through the design of instruments that allow evaluating the social factors of suicide during the pandemic and in general terms to improve people's lives.

\section{Funding Information}

This study was funded by the Autonomous University of Tamaulipas within the framework of the Project 38INVESTUAT2020 "Suicide in times of COVID-19: a victimological interpretation"

\section{Conflict of Interest}

There is not conflict of interest for this manuscript.

\section{References}

Agnoletti, M., Manganelli, S. \& Piras, F. (2020) Covid-19 and rural landscape: the case of Italy. Landscape and Urban Planning. Vol. 204:103955. DOI: https://doi.org/10.1016/j.landurbplan.2020.103955

Cheung, Y., Chau, O. \& Yip, P. (2008). A revisit on older adults suicides and Severe Acute Respiratory Syndrome (SARS) epidemic in Hong Kong. International Journal of Geriatric Psychiatry. Vol. 23(12):1231-1238. DOI: 10.1002/gps.2056

Dávila-Cervantes, C.,Ochoa-Torres, M. \& Casique-Rodríguez, I. (2015). Analysis of the impact of mortality due to suicides in Mexico, 2000-2012. Journal of Collective Health. Vol. 11(4): 471-484. DOI: http://dx.doi.org/10.18294/sc.2015.784

Goyal, K., Chauhan, P. Chhikara, K., gupta, P. \& Singh, M. (2020). Fear of COVID 2019: First suicidal case in India! Asian Journal of Psychiatry. Vol. 49: 101989. DOI: 10.1016/j.ajp.2020.101989

Gutiérrez-García, A., Contreras, C. \& Orozco-Rodríguez, R. (2006). Suicidio, conceptos actuales. Revista de Salud Mental. Vol. 29(5): 66-74. Available on: http://www.inprf-cd.gob.mx/pdf/sm2905/sm290566.pdf

Infobae (15 de Agosto de 2020). Creció el número de suicidios entre jóvenes mexicanos durante la emergencia sanitaria por COVID-19. Available on: https://www.infobae.com/america/mexico/2020/08/15/crecio-el-numero-de-suicidios-entre-jovenesmexicanos-durante-la-emergencia-sanitaria-por-covid-19/ 
Leaune, E., Samuel, M., Oh, H., Poulet, E. \& Brunelin, J. (2020). Suicidal behaviors and ideation during emerging viral disease outbreaks before the COVID-19 pandemic: A systematic rapid review. Preventive Medicine. Vol. 141: 106264. DOI: https://doi.org/10.1016/..ypmed.2020.106264

Griffiths, M. \& Mamun, M. (2020). Covid-19 suicidal behavior among couples and suicide pacts: Case study evidence from press reports. Psychiatry Research. Vol. 289:113105. Available on 10.1016/ j.psychres.2020.113105

Mcintosh, K. (2020). Coronavirus disease 2019 (COVID-19): Epidemiology, virology, and prevention. UpToDate. Available on: https://www.uptodate.com/contents/coronavirus-disease-2019-covid-19epidemiology-virology-and-prevention

National Institute of Statistic and Geography (INEGI) (2019a). Characteristics of registered deaths in Mexico in 2018.2 Available on: https://www.inegi.org.mx/contenidos/saladeprensa/boletines/2019/EstSociodemo/DefuncionesRegist radas2019.pdf

National Institute of Statistic and Geography (INEGI) (2019). Statistics for the purpose of the world day for the prevention of suicide (September 10) " national data 2019. Available on: https://www.inegi.org.mx/contenidos/saladeprensa/aproposito/2019/suicidios2019 Nal.pdf

National Institute of Statistic and Geography (INEGI) (2018). Statistics for the purpose of the world day for the prevention of suicide (September 10) " national data 2018. Available on: https://www.inegi.org.mx/contenidos/saladeprensa/aproposito/2018/suicidios2018 Nal.pdf

Pan American Health Organization (PAHO) (2020). COVID-19 pandemic exacerbates suicide risk factors. World Health Organization. Available on: https://www.paho.org/en/news/10-9-2020-covid-19pandemic-exacerbates-suicide-risk-factors

Posner, K., Oquendo, M., Gould, M., Stanley, B. \& Davies, M. (2007). olumbia Classification Algorithm of Suicide Assessment (C-CASA): Classification of Suicidal Events in the FDA's Pediatric Suicidal Risk Analysis of Antidepressants. American Journal of Psychiatry. Vol. 164(7): 1035-1043. DOI: $\underline{10.1176 / \text { appi.ajp.164.7.1035 }}$

Turecki, G. \& Brent, D. (2016). Suicide and suicidal behaviour. The Lancet. Vol. 387(10024): 1227-1239. DOI: https://doi.org/10.1016/S0140-6736(15)00234-2

Wasserman, M. (1992). The impact of epidemic, war, prohibition and media on suicide: United States, 19101920. Suicide and Life-Threatening Behavior. Vol. 22(2): 240-254. PMID: 1626335

World Health Organization (WHO) (2017). Mental health. The Global health observatory. Available on: https://www.who.int/data/gho/data/themes/mental-health

World Health Organization (WHO) (2020). Live life: preventing suicide. Department of Mental Health and Substance Abuse. Available on: https://www.who.int/docs/default-source/mental-health/suicide/livelife-brochure.pdf?sfvrsn=6ea28a12 2\&download=true 
Xiang, Y., Yang, Y., Li, W., Zhang, L., Zhang, Q., Cheung, T. \& H Ng, C. (2020). Timely mental health care for the 2019 novel coronavirus outbreak is urgently needed. Lancet Psychiatry. Vol. 7(3): 228-229. DOI: $10.1016 / \mathrm{S} 2215-0366(20) 30046-8$

Chang, Q., Yip, P. \& Chen, Y. (2019). Gender inequality and suicide gender ratios in the World. Journal of Affective Disorers. Vol. 243: 297-304. DOI: https://doi.org/10.1016/j.jad.2018.09.032

Expansión Política (September 10, 2020). The Secretary of Health reports 2,130 suicides between January and June of this year. Available on: https://politica.expansion.mx/mexico/2020/09/10/la-secretaria-desalud-reporta-2-130-suicidios-entre-enero-y-junio-de-este-ano

Sharifi, A. \& Khavarian-Garmsir, A. (2020). The COVID-19 pandemic: Impacts on cities and major lessons for urban planning, design, and management. Science of the Total Environment. Vol. 749: 142391. DOI: https://doi.org/10.1016/i.scitotenv.2020.142391

Sher, L. (2020). The impact of the COVID-19 pandemic on suicide rate. QJM: An International Journal of Medicine. Vol. 113(10): 707-712. DOI: https://doi.org/10.1093/qimed/hcaa202

D'Souza, D., Quadros, S., Hyderabadwala, Z. \& Mamun, M. (2020). Aggregate COVID-19 suicide incidences in India: Fear of COVID-19 infection is the prominent causative factor. Psychiatry Research. 290: 113145. DOI: 10.1016 / i.psychres.2020.113145 